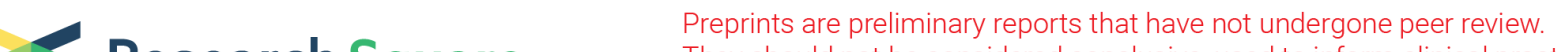 Research Square
or referenced bot be considered conclusive, used to inform clinical practice,
os validated information.
}

\section{Comparison of erythrocyte sedimentation rate between blood anticoagulated with sodium citrate and EDTA among Tuberculosis suspected patients at University of Gondar Hospital, North West Ethiopia}

Zegeye Getaneh ( $\square$ zegeyegetaneh91@gmail.com )

University of Gondar College of Medicine and Health Sciences https://orcid.org/0000-0002-8239-8491

Fekadu Ayelgn

University of Gondar College of Social Sciences and Humanities

\section{Geletaw Asemahegn}

University of Gondar

\section{Habtamu Geleta}

University of Gondar

\section{Aregawi Yalew}

University of Gondar College of Medicine and Health Sciences

\section{Tadele Melak}

University of Gondar College of Medicine and Health Sciences

\section{Research note}

Keywords: Erythrocyte sedimentation rate, EDTA, Tri-sodium citrate, Westergren Method, Comparison

Posted Date: December 26th, 2019

DOI: https://doi.org/10.21203/rs.2.16918/v2

License: (c) (i) This work is licensed under a Creative Commons Attribution 4.0 International License. Read Full License

Version of Record: A version of this preprint was published at BMC Research Notes on February 27th, 2020. See the published version at https://doi.org/10.1186/s13104-020-04963-0. 


\section{Abstract}

Objective: The purpose of this study was comparison of erythrocyte sedimentation rate results of sodium citrate and ethylene diamine tetra-acetic acid anticoagulant. A comparative cross-sectional study was conducted at University of Gondar Referral Hospital, Northwest, Ethiopia. A total of 70 TB suspected study participants were recruited. From each study participants, $3 \mathrm{ml}$ blood was collected in to EDTA tube and $1.6 \mathrm{ml}$ blood was collected in to a test tube containing $0.4 \mathrm{ml}$ Sodium Citrate anticoagulant. Results: The mean \pm SD values for ESR were $57.9 \pm 41.45$ in EDTA and $50.99 \pm 43.5$ in citrate anticoagulated blood. The mean difference of ESR values between EDTA and citrated blood was $6.91 \pm 13.66 \mathrm{~mm} / \mathrm{hr}$ with a significant difference. The mean \pm SD of ESR for EDTA and citrate blood was $59.57 \pm 42.31$ and $54.71 \pm 40.44 \mathrm{~mm} / \mathrm{hr}$ for males and $53.57 \pm 44.61$ and $46.04 \pm 41.82 \mathrm{~mm} / \mathrm{hr}$ for females, respectively. This study indicated that there was a significant difference between ESR values with EDTA and tri-sodium citrate anticoagulants.

\section{Introduction}

Erythrocyte sedimentation rate (ESR) is a common inexpensive, sensitive and non-specific hematology test frequently ordered in clinical medicine. It is the most widely used laboratory test for evaluating and monitoring of the course of infections, acute phase inflammation, autoimmune and malignant diseases. In addition, it serves as a general sickness index when it is used in conjunction with the patient's clinical history and physical examination (1-6).

Increased amount of the plasma proteins like fibrinogen are the major factors increasing the ESR test results by reducing the negative electrostatic force between red blood cells (RBCs) leading to an increased rate of rouleaux formation and the RBCs easily falling down within the plasma $(7,8)$. In case of inflammatory and infectious processes, the fibrinogen concentration in the blood increases the rouleaux formation and the RBCs settle faster than normal $(9,10)$.

An elevated ESR is often observed in cases of infectious diseases (active tuberculosis, bone infections and severe skin infections), malignancy, inflammatory or destructive processes and, auto immune diseases and rheumatic fever (11-13), collagen vascular disease and infective endocarditic $(12,13)$. It is also important for the assessment of severity of inflammatory bowel disease in children (14-17). It also has been used as a marker of response to treatment in tuberculosis $(18,19)$. Moreover, increased ESR can be an early predictive marker of HIV seropositive progression towards AIDS $(20,21)$. Additionally, increased ESR can be used as an inexpensive "sickness index" in the elderly (22).

Raised result of ESR is observed in a wide range of infectious, inflammatory, generative, malignant conditions and associated factors including anemia, pregnancy, hemoglobinopathies, hemoconcentration, and the treatment of anti-inflammatory drugs which changes the plasma proteins that increases in fibrinogen, immunoglobulin, and C-reactive protein $(23,24)$. 
The principle of the ESR determination is based on the measurements of the sedimentations rate of aggregated erythrocytes in plasma. The International Council for Standardization in Hematology (ICSH) recommended the Westergren method as the method of choice for ESR determination. When anticoagulated blood is placed in Westergren tube in vertical column, the erythrocytes normally settle quite slowly by the influence of gravity and the distance of erythrocytes falling down in a vertical column from the plasma in within one hour (25-27).

Undiluted specimens anticoagulated with EDTA reduce the risk of pre-analytic mistakes due to a partially coagulated specimen or to small clots, an altered blood/trisodium citrate (TSC) ratio, and problems linked to the final volume, inherent mainly in techniques using special tubes for both specimen collection and ESR measurement $(25,26)$. Using undiluted blood with K3EDTA is a recommended specimen for ESR determination by ICSH because it gives a more reliable result than the traditional $S C(27,28)$. However, according to the $2011 \mathrm{ICSH}$ recommendations, the reference method for the measurement of the ESR should be based on the Westergren method with modifications that use either whole blood anticoagulated with EDTA and later diluted with SC or saline (4:1) or whole blood anticoagulated with TSC (4:1) in Westergren pipettes (29).

Even though various researches were conducted in relation to ESR value among different disease, no studies have conducted on comparison of ESR value between blood mixed with SC and EDTA in the study area. Even though ESR test is one of the commonest investigations carried out in the clinical hematology laboratory, there is no recognized standard control sample available for monitoring the test.

The reliability and reproducibility of the results depends on the use of correct methodology. So, this study was aimed to assess the variability of the two commonly used anticoagulants.

\section{Methods And Materials}

\section{Study setting and population}

A comparative cross-sectional study was conducted on a total of 70 study subjects who come to the TB clinic at University of Gondar Comprehensive Specialized Hospital (UOGCSH) from March to May 2018. UOGCSH is found in Gondar town, Amhara regional state, Northwest Ethiopia. Gondar town is located at $727 \mathrm{~km}$ far from Addis Ababa and $185 \mathrm{~km}$ far from Bahir Dar town to the northwest part of the country. The town is situated at a latitude and longitude of $12^{\circ} 36^{\prime} \mathrm{N} 37^{\circ} 28^{\prime} \mathrm{E}$ with an elevation of 2133 meters above sea level.

All patients who come to the TB clinic and willing to participate during the study period and whose ages 15 and above were included in the study. Whereas, patients who did not give enough amount of blood sample, and who are not willing to participate in the study, were excluded from the study.

\section{Sample size determination}


A total of 70 study participants were recruited for this comparative cross-sectional study. A double population mean formula was used to calculate the required sample size using mean of citrate and EDTA taken from standard deviation and mean difference are taken from other studies (30) and 80\% power (0.84), $95 \%$ level of significance (1.96)

\section{Data collection and ESR determination}

Questionnaire and check lists prepared in English language and then translated to the local Language which is Amharic were used to collect the socio-demographic and clinical data of the study participants. Patient blood was collected both in the K3EDTA tubes (BD Vacutainer ${ }^{\circledR}$ Glass Tubes) and the TSC tubes (BD Vacutainer ESR glass tube). Five $\mathrm{ml}$ of venous blood was collected from each study participant in K3EDTA and TSC tubes. The citrate blood collection tube contained 3.8\% of TSC and EDTA blood collection tube contained $8 \mathrm{mg}$ of EDTA within it. Then $1.6 \mathrm{ml}$ of the whole blood sample was added to the $0.4 \mathrm{ml} \mathrm{3.8 \%} \mathrm{TSC} \mathrm{solution} \mathrm{and} 3 \mathrm{ml}$ of blood was added to EDTA tubes and immediately well mixed by inverting the tubes, three times. Then ESR values was done by Westergren method. For each participant, two tests of ESR determination were performed from each tube within 2 hours in accordance with the recommendation of ICSH (29). We filled the Westergren tube exactly to "0"mark and place the tube in the rack for 1 hour and the ESR results were recorded in $\mathrm{mm} / \mathrm{h}$. Then results from the K3EDTA tubes were compared to those of TSC tubes.

\section{Quality assurance}

Standard operating procedures (SOPs) and manufacturers' instruction were strictly followed for all laboratory activities as much as possible. All blood collection test tubes were checked for their expiry date and laboratory results were recorded on standard report formats using participants' identification number. The data of each patient were reviewed for the presence of mislabeling and completeness.

\section{Data analysis}

Epilnfo version 3.5.4 was used for data entry and SPSS version 20 for analysis. In this study, we used the paired t-test to determine any significant difference between the use of EDTA and TSC for ESR determination. The mean was used since it is the basis for all statistical computations and standard deviation was obtained to aid the computation of the t-value to measure the average amount of scatter in a distribution. To establish the relationship between the 2 methods, comparison studies were analyzed by simple least squares linear regression to obtain the $y$-intercept, the slope, and the SD of the regression line (Sy/x), and Pearson's correlation coefficient, and the data also were compared by the Altman-Bland analysis (31). Paired sample t-test at $95 \%$ confidence level was used to compare the two methods and in all cases P-value $<0.05$ was considered as statistically significant.

\section{Results}

Socio-demographic information 
A total of 70 TB suspected patients were included in the study. The study participants age ranged from 15 to 82 years but the majority were in the age group of 36-50 years, $21(30 \%)$. From the total study participants, majority $46(65.7 \%)$ were males and 21 (30\%) were aged between $36-50$ years. Forty-six $(65.7 \%)$ of them were from rural inhabitants (Table 1$)$.

\section{Comparison of ESR values between EDTA and TSC blood}

The mean \pm SD ESR values among patients were $57.9 \pm 41.45$ and $50.99 \pm 43.5$ using EDTA and TSC blood, respectively. The ESR value obtained from the study was higher in EDTA anticoagulant compared to TSC anticoagulant for all independent variables. The mean \pm SD of ESR for EDTA and citrate blood was $59.57 \pm 42.31$ and $54.71 \pm 40.44 \mathrm{~mm} / \mathrm{hr}$ for males and $53.57 \pm 44.61$ and $46.04 \pm 41.82 \mathrm{~mm} / \mathrm{hr}$ for females, respectively (Table 2 ).

The paired sample t-test analysis was done and showed that there was a statistically significant difference between the mean \pm SD of ESR values of the two anticoagulated blood. The mean difference of ESR values between the use of EDTA and TSC anticoagulated blood was $6.914 \mathrm{~mm} / \mathrm{hr}$. The computed t-value is $4.24(\mathrm{P}<0.0001 ; 95 \% \mathrm{Cl}: 3.66-10.17)$ which is greater than the tabulated t-value. Therefore, there is a significant difference between the use of EDTA and TSC as anticoagulant for ESR determination (Add. Table).

The Bland-Altman data analysis showed no systematic bias and $95 \%$ of all samples fell into the narrow $95 \%$ limits of agreement $(d-1.96 s d=6.914-[2 \times 13.661]=-20.408$ and $d+1.96 s d=6.914+[2 \times 13.661]=$ +34.236) (Figure 1). Linear regression analysis showed a satisfactory correlation between the two methods $\left(r=0.949, P<0.001 ; r^{2}=0.901 ; y=11.769+0.949 x ;\right.$ and $\left.S y / x=13.106\right)$ (Add. Figure).

\section{Discussion}

Even though ESR is not a specific marker for inflammation, currently, it is frequently used to help the diagnosis and evaluation or monitoring of patients with chronic diseases (32). The ESR value obtained from this comparison study showed that the mean value of EDTA anticoagulated blood $(57.90 \mathrm{~mm} / \mathrm{hr})$ was greater than that of TSC blood $(50.99 \mathrm{~mm} / \mathrm{hr})$ by $6.91 \mathrm{~mm} / \mathrm{hr}$. This may be due to EDTA increases rouleaux formation than TSC leading to increase ESR in EDTA blood or it might be a difference in viscosity, where citrated blood may be less viscous than EDTA blood resulting to lower ESR values in citrated blood (33-35). This observation coincides with the result reported from Tehran University, Iran, which stated that there was significant difference between the results of ESR test by using two anticoagulants (36).

The result of our study was also concurrent when compared to the study conducted in Nigeria, and its final finding was stated that mean \pm SD ESR value using EDTA anticoagulant is higher than mean \pm SD ESR value of the TSC. When compared to our finding, its result was within the normal range of ESR, the reason for this difference were the study participants as it was conducted from healthy individuals and our study was conducted on TB suspected patients which is one consequence for the increment of ESR 
value. In addition to this, the mean \pm SD ESR values of males were less than that of females which contradicts this finding. This may due to the fact that most of our male study participants were old aged and had a history of tuberculosis (30).

However, the result of our study was found to be in contrary with an earlier report conducted in India, which stated that the ESR measurement values of Citrated blood was greater by $4-6 \mathrm{~mm} / \mathrm{hr}$ than EDTA (10). Our study also contradicts a study conducted in India at Yenepoya University hospital patients. They found that the values of ESR using EDTA showed 4-6 mm/hr less than that of TSC. The authors recommended that ESR can be performed using EDTA blood instead of TSC since this utilizes only limited amount of blood for the procedure (9). A study carried out in Philippines got a mean ESR value of 36.7 and 43.09 for EDTA and TSC, respectively, which is not coincided with our finding. This may be due to some physiological and genetic differences between white and black men (37).

\section{Conclusion}

The calculated t-value is greater than 2; therefore, there is a significant difference from the values obtained using EDTA blood and TSC blood. We can conclude that EDTA blood yields a different results with TSC blood for ESRA determination. Therefore, it is better to use only one of the two anticoagulants consistently as there is a difference between them.

\section{Limitations}

The study was conducted at TB suspected and patients only and the study area was also limited in one district and therefore the result of the research may not be representative for the whole population.

\section{Abbreviations}

CBC: Complete blood count; EDTA: Ethylene diamine tetra acetic acid; ESR: Erythrocyte sedimentation rate; UoGCSH: University of Gondar Comprehensive Specialized Hospital; ICSH: International council for standardization in hematology; $\mathrm{K}_{3}$ EDTA: Tri potassium ethylene diamine tetra acetic acid; $\mathbf{m m} / \mathrm{hr}$. millimeter per hour; NCCLS: National committee for clinical laboratory standards; RBC: Red blood cells; SD: Standard deviation; TB: Tuberculosis; TSC: Trisodium citrate

\section{Declarations}

\section{Ethics approval and consent to participate}

Ethical clearance was obtained from School of Biomedical and Laboratory Sciences Research and Ethical Review Committee. Permission letter was obtained from the hospital director to conduct the study. The objectives of the research were explained to the study participants and written informed consent was taken. To ensure confidentiality of data, participants were identified using codes. 


\section{Consent to publish}

Not applicable.

\section{Availability of data and materials}

All the data on which the conclusions of this manuscript are drawn are available in the corresponding author. So that any who needs the data can get it upon reasonable request.

\section{Competing interests}

The authors declare that there is no any conflict of interest regarding the publication of this work.

\section{Funding}

The author(s) received no specific funding for this work

\section{Authors' Contributions}

ZG, FA, GA and HG were participated in designing the study, supervised the data collection, analyzed, interpret and write up the manuscript. FA, GA, HG, AY and TM were involved in proposal development, data collection and entry of data for analysis. TM and ZG are the joint first authors of the paper. All authors read and approved the final drafted manuscript.

\section{Acknowledgements}

The authors would like to acknowledge the study participants, University of Gondar hospital TB clinic and Laboratory staffs for their collaboration. We would also thank to the University of Gondar, College of Medicine and Health Sciences, School of Biomedical and Laboratory Sciences for all the supports and collaborations in general.

\section{References}

1. Mahlangu JN, Davids M. Three-way comparison of methods for the measurement of the erythrocyte sedimentation rate. Journal of clinical laboratory analysis. 2008;22(5):346-52.

2. Ozdem S, Akbas HS, Donmez L, Gultekin M. Comparison of TEST 1 with SRS 100 and ICSH reference method for the measurement of the length of sedimentation reaction in blood. Clinical Chemistry and Laboratory Medicine (CCLM). 2006;44(4):407-12.

3. Musa RJ, Mansoor SS, and, Ali HH. Westergren Sedimentation Rate using K3EDTA. Iranian J Med Sci. 2004;3(2):132-5.

4. Salehzadeh F, Noshin A, Jahangiri S. IVIG effects on erythrocyte sedimentation rate in children. International journal of pediatrics. 2014;2014. 
5. Hoffbrand AV, Moss PA. Essential haematology. 6th ed: West Sussex: John Wiley \& Sons; 2011. p.

6. Dewi MMW, Herawati S, Mulyantari NK, Prabawa IPY. The comparison of erythrocyte sedimentation rate (ESR) modify Westergren Caretium Xc-A30 and Westergren Manual in Clinical Pathology Laboratory, Sanglah General Hospital, Denpasar, Bali.

7. Educational Commentary- the Erythrocyte Sedimentation Rate and its clinical utility. American Proficiency Institute - 2006 2nd Test Event.

8. Mack DR, Langton C, Markowitz J, LeLeiko N, Griffiths A, Bousvaros A, et al. Laboratory values for children with newly diagnosed inflammatory bowel disease. Pediatrics. 2007;119(6):1113-9.

9. Kumta S, Nayak G, Kedilaya H P, and, Shantaram M. A COMPARATIVE STUDY OF ERYTHROCYTE SEDIMENTATION RATE (ESR) USING SODIUM CITRATE AND EDTA. International Journal of Pharmacy and Biological Sciences IJPBS. 2011;1(4):393-6.

10. Brigden M. The erythrocyte sedimentation rate: still a helpful test when used judiciously. Postgraduate medicine. 1998;103(5):257-74.

11. Go DJ, Lee EY, Lee EB, Song YW, Konig MF, Park JK. Elevated erythrocyte sedimentation rate is predictive of interstitial lung disease and mortality in dermatomyositis: a korean retrospective cohort study. Journal of Korean medical science. 2016;31(3):389-96.

12. Saadeh $C$. The erythrocyte sedimentation rate: old and new clinical applications. SOUTHERN MEDICAL JOURNAL-BIRMINGHAM ALABAMA-. 1998;91:219-26.

13. Brigden ML. Clinical utility of the erythrocyte sedimentation rate. American family physician. 1999;60(5):1443-50.

14. Bain B. Some influences on the ESR and the fibrinogen level in healthy subjects. Clinical \& Laboratory Haematology. 1983;5(1):45-54.

15. Zlonis $\mathrm{M}$. The mystique of the erythrocyte sedimentation rate: a reappraisal of one of the oldest laboratory tests still in use. Clinics in laboratory medicine. 1993;13(4):787-800.

16. Gabay C, Kushner I. Acute-phase proteins and other systemic responses to inflammation. New England journal of medicine. 1999;340(6):448-54.

17. Fabry TL. Mechanism of erythrocyte aggregation and sedimentation. Blood. 1987;70(5):1572-6.

18. Mahalakshamamma V, Raju E, Jhansi K. Erythrocyte Sedimentation Rate Values In Pulmonary Tuberculosis Versus Normal Healthy Peoples In Khammam Region Of Telangana, India. International Journal Of Integrative Medical Sciences. 2016;3:207-10.

19. Mandal SK, Chavan L. Erythrocyte Sedimentation Rate Values in Cases of Active Tuberculosis without HIV Co-Infection. Journal of Medical Science And clinical Research. 2016;4(10):13156-9.

20. Lefrere J, Salmon D, Doinel C, Rouger P, Courouce A, Lambin P, et al. Sedimentation rate as a predictive marker in HIV infection. AIDS (London, England). 1988;2(1):63.

21. Foromera J. Diagnostic and Prognostic Value of ESR and CRP in HIV Positive Adults in Durban, South Africa 2018. 
22. Wolfe F, Michaud $\mathrm{K}$. The clinical and research significance of the erythrocyte sedimentation rate. The Journal of Rheumatology. 1994;21(7):1227-37.

23. Cheesbrough M. District laboratory practice in tropical countries: Cambridge university press; 2006.

24. Thue G, Sandberg S, Fugelli P. The erythrocyte sedimentation rate in general practice: clinical assessment based on case histories. Scandinavian journal of clinical and laboratory investigation. 1994;54(4):291-300.

25. Horsti J, Kovanen M. Using EDTA as an anticoagulant for ESR to replace citrate. Kliin lab. 2000;4:97100.

26. Koepke J, Van Assendelft O, Bull B, Richardson-Jones A. Standardization of EDTA anticoagulation for blood counting procedures. Labmedica. 1988;1989:5.

27. International Council for Standardization in Haematology. ICSH recommendation for measurement of erythrocyte sedimentation rate. J Clin Pathol. 1993; 46: 198-203.

28. National Committee for Clinical Laboratory Standards. Reference and Selected Procedure for Erythrocyte Sedimentation Rate (ESR) Test; Approved Standard, 4th ed. H2-A4. Villanova, PA: NCCLS; 2000.

29. Jou J, Lewis S, Briggs C, LEE SH, De La Salle B, McFadden S, et al. ICSH review of the measurement of the erythocyte sedimentation rate. International journal of laboratory hematology. 2011;33(2):12532.

30. Emelike O, Akpan J, Obigwe B, Jeremiah Z. Comparative Study of Erythrocyte Sedimentation Rate (ESR) Using Trisodium Citrate, Normal Saline and Whole Blood in Ethylene Di Amine Tetra Acetic Acid (EDTA). Journal of Applied Sciences and Environmental Management. 2010;14(1).

31. Altman DG, Bland JM. Assessing agreement between methods of measurement. Clinical chemistry. 2017;63(10):1653-4.

32. Fischbach FT, Dunning III MB, . A Manual of Laboratory and Diagnostic Test. . 9th ed. Philadelphia Wolters Kluwer Health | Lippincott Williams \& Wilkins; 2015.

33. Lawrence JS. Assessment of the Activity of Disease: Lewis; 1961.

34. Hardwicke J, Squire J. The basis of the erythrocyte sedimentation rate. Clinical science. 1952;11(4):333.

35. Furukawa K, Abumiya T, Sakai K, Hirano M, Osanai T, Shichinohe H, et al. Increased blood viscosity in ischemic stroke patients with small artery occlusion measured by an electromagnetic spinning sphere viscometer. Journal of Stroke and Cerebrovascular Diseases. 2016;25(11):2762-9.

36. Maghsood, R. Geransar A. Jahanzad E., Jahanzad L., A comparative study on the effect of sodium citrate and EDTA in ESR after one and two hours in children and adults, Tehran University of Medical Sciences. ijp.tums.ac.ir: 2005: 15 (2).

37. Jay M, Lorraine comparison of ESR among patients of Cebu doctors' hospital using EDTA and citrated blood, at Cebu Doctors' university 1998. 


\section{Tables}

Table 1: Socio-demographic information of the study participants $(\mathrm{N}=70)$

\begin{tabular}{llll}
\hline Characteristics & & Frequency & Percent (\%) \\
\hline Sex & Male & 46 & 65.7 \\
& Female & 24 & 34.3 \\
Age in years & $15 \_25$ & 17 & 24.3 \\
& $26 \_35$ & 18 & 25.7 \\
& $36 \_50$ & 21 & 30 \\
& $>50$ & 14 & 20 \\
Religion & Muslim & 9 & 12.9 \\
& Orthodox & 61 & 87.1 \\
Residence & Rural & 46 & 65.7 \\
& Urban & 24 & 24.3 \\
\hline
\end{tabular}

Table 2: Mean \pm SD ESR values of the study participants using EDTA and TSC Whole Blood.

\begin{tabular}{llcc}
\hline Variables & Category & \multicolumn{2}{c}{ Mean and SD of ESR in mm/hr } \\
& & EDTA & TSC \\
\cline { 2 - 3 } & & Mean \pm SD & Mean \pm SD \\
\hline Sex & M & $59.57 \pm 42.31$ & $53.57 \pm 44.61$ \\
Age in year & $15-25$ & $54.71 \pm 40.44$ & $46.04 \pm 41.82$ \\
& $26-35$ & $56.78 \pm 43.07$ & $28.88 \pm 36.26$ \\
& $36-50$ & $62.52 \pm 43.10$ & $41.11 \pm 45.91$ \\
Residence & $>50$ & $78.36 \pm 32.73$ & $69.43 \pm 37.09$ \\
& Rural & $54.76 \pm 41.08$ & $47.80 \pm 42.55$ \\
Previous TB History & Yrban & $63.92 \pm 42.36$ & $57.08 \pm 45.61$ \\
& Nos & $69.71 \pm 41.20$ & $65.00 \pm 43.86$ \\
TB Status & Positive & $54.11 \pm 41.20$ & $46.49 \pm 42.85$ \\
Total & Negative & $54.48 \pm 41.65$ & $47.48 \pm 42.76$ \\
\hline
\end{tabular}

$\mathrm{SD}=$ standard deviation 
Figures

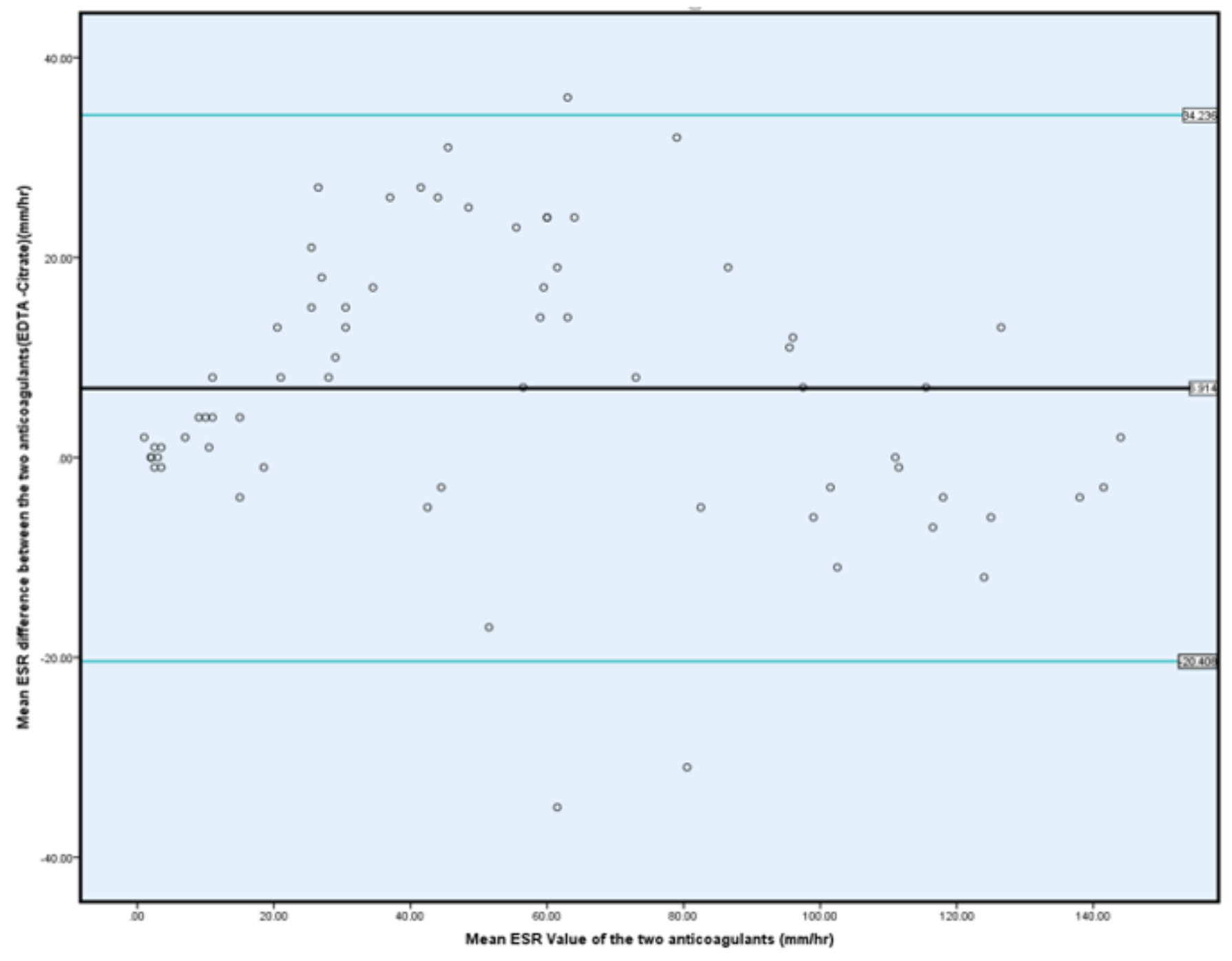

Figure 1

Bland-Altman plot of ESR values from the EDTA and the TSC whole blood using manual Westergren method

\section{Supplementary Files}

This is a list of supplementary files associated with this preprint. Click to download.

- Methodsformula.docx

- Additionalfiles.docx 